\title{
Occurrence and fertility rates of hydatid cysts in sheep and goats slaughtered at Modjo Luna Export Slaughter House, Ethiopia
}

\author{
Daniel Getachew ${ }^{1}$, Gizat Almaw ${ }^{2 *}$, Getachew Terefe ${ }^{3}$ \\ ${ }^{1}$ Lume Agricultural Animal Health Agency, Modjo \\ ${ }^{2}$ National Animal Health Diagnostic and Investigation Center, PO Box 04, Sebeta \\ ${ }^{3}$ Department of Veterinary Pathology and Parasitology; Faculty of Veterinary Medicine, Addis \\ Ababa University, PO Box 34, Debre Zeit, Ethiopia \\ *Correspondent author: Gizat Almaw E-mail: tiwawyedegera@yahoo.com
}

\begin{abstract}
In Ethiopia very limited studies were conducted in small ruminant hydatidosis compared to cattle. A cross-sectional study was conducted at Modjo Luna Export Slaughter House from December 2009 to February 2010 to determine the prevalence and fertility of hydatid cysts. A total of 325 sheep and 440 goats were examined. Examination of lung, liver, kidney, heart and carcass was conducted following standard postmortem procedures. Fertility of hydatid cysts was tested by absence or presence of motility and staining with $0.1 \%$ aqueous eosin solution. Out of 325 sheep and 440 goats examined 25 (7.7\%) sheep and 27(6.13\%) goats had hydatid cysts. The prevalence was high in sheep compared to goats although the difference was not statistically significant $(\mathrm{P}>0.05)$. The organ distribution of hydatid cyst in sheep was 15 (60\%) in lung, 9 (36\%) in liver and 1 (4\%) both the liver and lungs. In goats, hydatid cysts were recovered from 19 (70\%) of the lung, 5 (18.5\%) of the liver, $1(3.7 \%)$ of the kidney, $2(7.4 \%)$ of the heart and $2(7.4 \%)$ of the muscle. In both sheep and goats the infection was more in lungs, followed by liver. Eighty percent of the cysts found in the lung of sheep were fertile, while there was no fertile cyst detected in the lung of goats and the difference was statistically significant $(\mathrm{P}$ $<0.05)$. In Ethiopia, to break the life cycle of echinococcosis/hydatidosis, public education on habit of feeding condemned organs to dogs should be undertaken.
\end{abstract}

Keywords: hydatid cyst, prevalence, fertility, sheep, goat, Modjo Luna Export Slaughter House

http://dx.doi.org/10.4314/evj.v16i1.7 


\section{Introduction}

Echinococcosis/hydatidosis is a zoonotic disease that occurs throughout the world and causes considerable economic losses and public health problems in many countries. Sheep, goats, cattle, camels, buffaloes, pigs, horses and donkeys have been repeatedly found infected with hydatid cysts (Dalimi et al., 2002; Lahmar et al., 2004; Daryani et al., 2006; Acosta-Jamett et al., 2010). The global hyatidosis infection prevalence rates reported were $22.98 \%$ in cattle, $10.58 \%$ in sheep, $12.03 \%$ in camels, $17.80 \%$ in equines and $1.88 \%$ in goats (Azlaf and Dakkak, 2006). According to Dakkak (2010) in his review of published data prevalence of hydatidosis is high in North Africa, Turkey, Greece and in several regions of Italy and Spain. Previous reports indicated that the prevalence of hydatidosis is high in sheep compared to goats. In sheep, it ranges from $10.6 \%$ to $75 \%$ and in goats $1.88 \%$ to $6.3 \%$ (Dalimi et al., 2002; Azlaf and Dakkak, 2006; Scala et al., 2006; Christodoulopoulos et al., 2008 ; Nigatu Kebede et al., 2009; Acosta-Jamett et al., 2010; Omer et al., 2010). In Ethiopia hydatidosis is the major cause of organ condemnation in most abattoirs (Gebretsadik Berhe, 2009; Nigatu Kebede, 2010; Feyesa Regassa et al., 2010) and leads to huge economic losses. It is also a disease of public health importance in Ethiopia where in Tigray Regional State nine cases of human hydatidosis were reported since 2000 (Nigatu Kebede et al., 2009). While there are several works done in bovine species, little attention is paid to investigate the prevalence and economic significance of hydatidosis in small ruminants in Ethiopia. It is also important to study the fertility of hydatid cysts as it will help to understand the risk of spreading of the disease both to domestic animals and humans. The main objectives of this study were therefore to estimate the prevalence of hydatidosis in small ruminants slaughtered at Modjo Luna Export Slaughter House and determine the fertility of the cysts.

\section{Materials and Methods}

\section{Study area}

The study was conducted at Modjo Luna Export Slaughter House, which is located $70 \mathrm{~km}$ south east of Addis Ababa, the capital city of Ethiopia. Modjo Luna Export Slaughter House is the first and the largest abattoir in Modjo town. It is established in 2002 and an average of 22,000 sheep and goats are slaughtered every month for export purpose. 


\section{Study animals}

All sheep and goats slaughtered were males. The origins of the animals were different areas in the country including Wollo, Metehara, Afar, Ogaden, Bale and surrounding areas of the slaughter house. The animals were purchased from farmers on weight basis and those below 10-12 kg were rejected. The husbandry practice for these animals was mainly grazing. The age of the slaughtered sheep and goats ranges from one to two years.

\section{Study type and sample size determination}

The study was a cross- sectional study. The study animals were small ruminants (325 sheep and 440 goats) slaughtered at Modjo Luna Export Slaughter House between December 2009 and February 2010. The required sample size was determined as described by Thrusfield (2005). The expected prevalence of hydatidosis was taken from previous work of Lobago (1994, unpublished) at Konso abattoir which was $9.3 \%$ in sheep and $18.8 \%$ in goats. And by setting 95\% confidence level and 5\% desired level of precision; the sample size was calculated to be 130 sheep and 235 goats. However, 325 sheep and 440 goats were sampled so as to increase the precision of the study.

\section{Postmortem examination}

Postmortem examination was conducted three days per week and the days were selected on the basis of number of animals slaughtered during those days. Visual inspection, palpation and systematic incision of each visceral organ particularly the liver, lung, heart, kidney and carcass were carried out according to procedures recommended by FAO (1994). Spleen was not examined in this study due to inconvenience in the arrangement of the abattoir for sampling during the study.

\section{Examination of cyst fertility}

Cyst fertility was examined according to Daryani et al. (2006). Briefly, individual cysts were grossly examined for degeneration, then according to the size (not too small) hydatid cysts in sheep and goats were selected for fertility study. To reduce intracystic pressure, the cyst wall was penetrated, using needle and it was cut with scalpel and scissors. The contents were then transferred into a sterile container. The cysts were classified as sterile (fluid filled cyst without any protoscoices), calcified, non viable (cysts with dead protoscoices) and viable or fertile (cysts with live protoscoices). To determine viability of the protoscolices, a drop of cyst fluid was placed on a microscopic glass slide and 
cover slip was applied and observed for the motility of flame cells activity like peristaltic movement. When it becomes doubtful for motility, a drop of $0.1 \%$ aqueous eosin solution was added and examined under a light Microscope for taking the dye. Live protoscolices did not take the dye whereas, the dead ones did.

\section{Data analysis}

Descriptive statistics was used to summarize the data. For comparison of prevalence of hydatidosis in sheep and goats and viability of cysts between lung and liver $x^{2}$ and Fisher exact using Intercooled Stata 7.0 were used.

\section{Results}

\section{Prevalence of hydatidosis}

Out of 325 sheep examined, 25 had hydatid cysts in various organs, giving an overall prevalence of $7.7 \%$. Twenty seven goats out of $440(6.13 \%)$ were found positive for hydatid cysts (Table 1). The prevalence was higher in sheep compared to goats but the difference was not statistically significant $(\mathrm{P}>$ $0.05)$.

Table 1: Prevalence of hydatidiosis in sheep and goats slaughtered at Modjo Luna Slaughter House from December 2009 - February 2010.

\begin{tabular}{lccc}
\hline Species of animal & No. Examined & Hydatid positive & Prevalence (\%) \\
\hline Sheep & 325 & 25 & 7.7 \\
Goats & 440 & 27 & 6.13 \\
Total & 765 & 52 & 6.8 \\
\hline
\end{tabular}

By organ distribution hydatid cyst was found more often in lung and liver. Out of 25 sheep with hydatid cysts, 15 (60\%) harbored hydatid cysts in lung, 9 (36 $\%)$ in liver and 1(4\%) involved both lung and liver. Similarly in goats, out of 27 with hydatid cysts, lungs accounted for 19 (70 \%), liver 5(18.5 \%), kidney 1(3.7 $\%)$, heart 2 (7.4 \%) and 2 (7.4\%) harbored hydatid cysts in muscle (Table 2 ).

Table 2: Distribution of hydatid cysts in different organs of infected sheep and goats slaughtered at Modjo Luna Slaughter House from December 2009 - February 2010.

\begin{tabular}{lccccccc}
\hline Animals & No. Examined & Lung & Liver & Kideny & heart & Muscle & Liver and lung \\
\hline Sheep & 325 & $15(60 \%)$ & $9(36 \%)$ & 0 & 0 & 0 & $1(4 \%)$ \\
Goat & 440 & $19(70 \%)$ & $5(18.5 \%)$ & $1(3.7 \%)$ & $2(7.4 \%)$ & $2(7.4 \%)$ & 0 \\
\hline
\end{tabular}




\section{Hydatid cyst fertility}

In sheep, a total of 25 cysts were examined to identify cyst fertility or viability. From those $5(20 \%), 5(20 \%), 9(36 \%)$ and $6(24 \%)$ were identified as fertile, non viable, sterile and calcified, respectively. Fertile cysts were mostly detected in lung which were 4 (80\%) of the whole fertile cysts. However, most of cysts in the liver $3(50 \%)$ ) were found calcified (Table 3). Viable cysts were higher in lungs compared to liver although not statistically significant $(p>0.05)$. In goats, a total of 27 cysts were examined to identify cyst fertility. From those $6(22.20 \%)$, 9 (33.30\%), 5 (18.5\%), 10(37.03\%) were identified as fertile, non viable, sterile and calcified, respectively. From a total of 19 lung cysts there was no fertile cyst detected in goats. Rather non-viable cysts in goats were found mostly in lungs which were $7(36.8 \%)$ of the whole cysts (Table 3). Generally, there was no significance difference in viability of hydatid cysts between sheep and goats (20\% in sheep and $22.20 \%$ in goats) $\left(\mathrm{X}^{2}(1)=0.0403 \mathrm{P}=0.841\right)$. However, the proportion of viable cysts found on lung were high in sheep 4 (80\%) and there was no viable cyst found in goat's lung and the difference was statistically significant $(\mathrm{P}<0.05)$.

Table 3 Classification of hydatid cysts collected from sheep and goats slaughtered at Modjo Luna Slaughter House from December 2009 - February 2010 based on viability of cysts.

\begin{tabular}{lcccccccccc}
\hline \multirow{2}{*}{ Organs } & \multicolumn{2}{c}{ Viable } & \multicolumn{2}{c}{ Non Viable } & \multicolumn{2}{c}{ Sterile } & \multicolumn{2}{c}{ Calcified } & \multicolumn{2}{c}{ Total } \\
\cline { 2 - 10 } & Sheep & Goats & Sheep & Goats & Sheep & Goats & Sheep & Goats & Sheep & Goats \\
\hline Liver & 1 & 1 & 2 & 1 & 3 & 2 & 3 & 1 & $9(36 \%)$ & $5(18.5 \%)$ \\
Lung & 4 & 0 & 3 & 7 & 6 & 3 & 2 & 9 & $15(60 \%)$ & $19(70.4 \%)$ \\
Liver and lung & 0 & 0 & 0 & 1 & 0 & 0 & 0 & 0 & $1(4 \%)$ & 0 \\
Kidney & 0 & 1 & 0 & 0 & 0 & 0 & 0 & 0 & 0 & $1(3.7 \%)$ \\
Heart & 0 & 2 & 0 & 0 & 0 & 0 & 0 & 0 & 0 & $2(7.4 \%)$ \\
Muscle & 0 & 2 & 0 & 0 & 0 & 0 & 0 & 0 & 0 & $2(7.4 \%)$ \\
\hline
\end{tabular}

\section{Discussion}

Hydatidosis is known to be livestock and public health important disease and for establishment of a control strategy, detailed information on local epidemiology and significance of the disease must be known. In the current study, the prevalence of hydatidosis in sheep was found to be $7.7 \%$. A slightly higher prevalence (10.6\%) was reported at Bhir Dar, Ethiopia (Nigatu Kebede et al., 2009). In Libya Dalimi et al. (2002) reported a prevalence rate of $8.7 \%$ comparable to the present finding. In sheep prevalences ranging from $10.6 \%$ to $75 \%$ were reported in different countries (Dalimi et al., 2002; Azlaf and Dakkak 
2006; Scala et al., 2006; Woldegeorgis Kebede et al., 2009; Omer et al., 2010; Christodoulopoulos et al., 2008 ; Acosta-Jamett et al., 2010). These variations of the infection rates could be due to the variations in the temperature, environmental conditions, and the way of raising of these animals. In goats Tariku Jebat et al. (2008) in Ethiopia reported 1.7\% prevalence lower than the current study (6.13\%). The global hyatidosis infection prevalence rate was $1.88 \%$ in goats (Azlaf and Dakkak, 2006). The available literature mentioned in this manuscript or elsewhere showed that the prevalence of hydatidosis is high in sheep compared to goats. This may be due to the difference in feeding habits that goats are browsers.

In the present study, lungs were found to be more involved in sheep (60\%) and goats (70\%) followed by liver which goes with the findings of Khan et al. (2001) and Dalimi et al. (2002) who had reported that lungs were the most affected organ compared to liver. Other workers had also found results in support of the present finding (Islam et al., 2003; Nigatu Kebede et al., 2009). The reason for higher prevalence of cysts in lung might be due to softer consistency of lungs.

Hydatid cyst, though known to occur in many areas of the body, is rare in skeletal muscle. Echinococcosis of muscle is caused by the larval stage of Echinococcus granulosus or, rarely, by the more aggressive Echinococcus multilocularis. Hydatidosis of muscle appears to be uncommon, as muscle is involved in only $3 \%$ of echinococcal infection (Latino et al., 1999). In the present study $4 \%$ of echinococcal infection was involved in goat muscle. The findings in the present study correspond to the earlier observations with regard to organ involvement of hydatidosis.

With regard to fertility of cysts, in sheep (lung, 80\% and liver, 20\%) fertile cysts were common. In agreement with the present study Alemian et al. (2007) have reported that the fertility of pulmonary cysts in sheep was higher than those of hepatic cysts. Anwar et al (1993) reported the fertility rate of $80.95 \%$ in sheep (81.62\% in lungs, $78.92 \%$ in liver). Scala et al. (2006) and Ahmed et al. (2006) also showed that in sheep, pulmonary fertile cysts were higher than those in liver. However, Dalimi et al., (2002) reported that the fertility of cysts in liver of sheep (36.9\%) in western Iran was higher than that in the lungs (25.2\%). Gusbi et al (1987), Kamhawi et al (1995), and Saeed et al (2000) have also reported that the hepatic cysts of sheep were more fertile than those in the lungs. Khan et al. (2001) reported that in sheep the fertility of cysts in the liver was similar to that of the cysts in the lungs. Variation in fertility rate 
among the organs might be due to the difference in tissue resistance among of the organs (Arene, 1985).

In conclusion the present study on sheep and goats revealed that hydatidosis is a major cause of organ and carcass condemnation and financial loss to Modjo Luna Export Slaughter House in particular and to the country at large. The prevalence rate of hydatidosis was high in sheep compared to goats and in both species lung was the most frequently affected organ by hydatid cyst followed by liver. The cysts found in the lung of sheep were fertile, while there was no fertile cyst detected in the lung of goats. In Ethiopia, it is a common practice to feed dogs condemned organs which would maintain the life cycle of the disease and therefore public education has to be considered.

\section{Acknowledgments}

The authors would like to thank the veterinarians and the staff member of Modjo Luna Export Slaughter House for their technical support.

\section{References}

Acosta-Jamett, G., Cleaveland, S., Cunningham, A. A., Bronsvoort, B. M. C., Craig. P. S., 2010. Echinococcus granulosus infection in humans and livestock in the Coquimbo region, north-central Chile. Vet. Parasitol. 169, 102-110

Ahmed, S., Nawaz, M., Gul, R., Zakir, M., Razzaq, A., 2006. Some epidemiological aspect of hydatidosis of lungs and livers of sheep and goats in Quetta, Pakistan J. Zool., 38(1), 1-6.

Alemian, S., Karimi, G., Rivaz, S., 2007. Fertility and viability of protoscoleces of hydatid cysts of sheep slaughtered in slaughter house of Chaharmahal-o-Bakhtiari. National congress of hydatid cyst. Iran Quarterly Journal of Yasouj University of Medical Sciences. 12, 76

Anwar, A. H., Haq, A. U., Gill, S. A., Chaudhry, A. H., 1993. Prevalence and fertility ratio of hydatid cyst in slaughtered sheep and goats at Faisalabad. Pakistan Vet. J., $13,79-81$

Arene, F. O. I., 1985. Prevalence of hydatidosis in domestic live stock in the Niger Delta. Trop. Anim. Hlth. Prod. 17, 3-4

Azlaf, R. Dakkak, A., 2006. Epidemiological study of the cystic echinococcosis in Morocco. Vet. Parasitol. 137, 83-93.

Ethiop. Vet. J., 2012, 16 (1), 83-91 
Berhe, G., 2009. Abattoir survey on cattle hydatidosis in Tigray Region of Ethiopia. Trop.Anim. Hlth. Prod. 41, 1347-1352.

Christodoulopoulos, G., Theodoropoulos, G., Petrakos, G., 2008. Epidemiological survey of cestode-larva disease in Greek sheep flocks. Vet. Parasitol. 153, 368-373.

Dakkak, A., 2010. Echinococcosis/Hydatidosis: a severe threat in Mediterranean countries. Vet. Parasitol. doi:10.1016/j.vetpar.2010.08.009

Dalimi, A., Motamedi, G., Hosseini, M., Mohammadian, B., Malaki, H.,. Ghamari, Z., Ghaffari, F., 2002. Echinococcosis/hydatidosis in western Iran. Vet. Parasitol. 105, 161-171

Daryani, A., Aiaei, R., Arab, R., Sharif, M., 2006. Prevalence of hydatid cyst in slaughtered animals in Northwest Iran. J. Anim. Vet. Adv. 5, 330-334.

FAO., 1994. Meat inspection manual for developing countries. Rome. Animal and health production papers. Food and Agriculture Organization of the United Nations.

Gusbi, A. M., Awan, M. A. Q., Beesley, W. N., 1987. Echinococcosis in Libya: Prevalence of hydatidosis Echinococcos granulosus in goats, cattle and camels. Ann. Trop. Med. Parasit. 84, 477-482.

Intercooled Stata 7.0, 1985-2001. Statistics/Data Analysis Texas, USA, Stata Corporation

Islam, M.K., Basaka, S. C., Majumder, S., Sarder, S. A., Islam, A. W. M. S., Mondal, M. M. H., 2003. Cystic echinococcosis in domestic ruminants in Cox's Bazar of Bangladesh. Pak. J. Sci. Ind. Res. 46, 251-254

Jibat T., Ejeta G., Asfaw Y., and Wudie A. 2008. Causes of abattoir condemnation in apparently healthy slaughtered sheep and goats at HELMEX abattoir, Debre Zeit, Ethiopia. Revue Méd. Vét., 159, 305-311

Kamhawi, S., Hijjawi, N., Abu-Ghazaleh, A., Abbas, M., 1995. Prevalence of hydatid cysts in livestock from five regions in Jordan. Ann. Trop. Med. Hyg. 89, 621-629.

Kebede, N. 2010. A retrospective survey of bovine hydatidosis in three abattoirs of Amhara National Regional State, northwestern Ethiopia. Trop. Anim. Hlth. Prod. 42, 323-325.

Kebede, N., Mitiku, A. and Tilahun, G., 2009. Hydatidosis of slaughtered animals in Bahir Dar Abattior, Northwestern Ethiopia.Trop. Anim. Health. Prod. 41, 43-50 
Kebede, W., Hagos, A., Girma, Z. and Lobago, F., 2009. Echinococosis/hydatidosis: its prevalence and public health. Trop. Anim. Health. Prod. 41, 865-871.

Khan, A.H., El-Buni, A.A. and Ali, M.Y., 2001. Fertility of cysts of Echinococcos granulosus in domestic herbivores from Benghazi, Libya and the reactivity of antigens produced from them. Ann. Trop. Med. Parasit. 95, 337-342.

Lahmar S., Debbeka H., Zhang L.H., McManus D.P, Souissi A., Chelly S., Torgerson P.R, 2004 . Transmission dynamics of the Echinococcus granulosus sheep-dog strain (G1 genotype) in camels in Tunisia. Vet. Parasitol. 121, 151-156.

Latino, R., Costa, S., Barbagallo, E., Virzi, A., Vagnoni, G., 1999. Primary localization of hydatid cyst in the major dorsal muscle: report of case. Ann Ital Chir. 70, 123-6.

Omer, R.A., Dinkel, A., Romig, T., Mackenstedt, U., Elnahas, A.A., Aradaib, I.E., Ahmed, M.E., Elmalik, K.H., Adam, A., 2010. A molecular survey of cystic echinococcosis in Sudan. Vet. Parasitol. 169, 340-346.

Regassa, F., Molla,A., Bekele, J., 2010. Study on the prevalence of cystic hydatidosis and its economic significance in cattle slaughtered at Hawassa Municipal abattoir, Ethiopia. Trop. Anim. Health. Prod., 42, 977-984.

Saeed, I., Kapel, C., Saida, L. A., Willingham, L., Nansen, P., 2000. Epidemiology of Echinococcosis granulosus in Arbil province, norther Iraq. J. helminthol. 74, 8388.

Scala, A., Garippa, G., Varcasia, A., Tranquillo, V. M., Genchi, C., 2006. Cystic echinococcosis in slaughtered sheep in Sardinia (Italy). Vet. Parasitol. 135, 33-38.

Thrusfield, M., 2005. Veterinary Epidemiology. $3^{\text {rd }}$ ed. Singapore, Black well Science. p. 233. 
